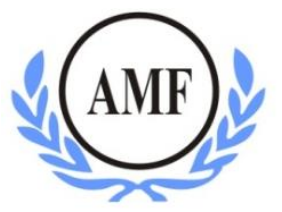

\title{
A INFLUÊNCIA DAS CULTURAS REGIONAIS NO DESENVOLVIMENTO DE LIDERANÇAS E NO PROCESSO DE SATISFAÇÃO
}

\author{
Lenilton Oliveira da Silveira ${ }^{1}$ \\ Thiago Kader Rajeh Ibdaiwi ${ }^{2}$ \\ Sheila De Oliveira Goulart ${ }^{3}$ \\ Damiana Machado de Almeida ${ }^{4}$ \\ Vivian Pereira Munró ${ }^{5}$ \\ Jonathan Saidelles Corrêa ${ }^{6}$
}

\begin{abstract}
Resumo
O presente estudo tem o objetivo de verificar a satisfação e retenção dos gestores administrativos, em uma grande empresa do varejo, analisando duas diferentes regiões do Brasil. Buscaram-se definições teóricas apresentadas na revisão de literatura, com conceitos sobre satisfação e retenção de colaboradores, a importância de se mantê-los satisfeito, a evolução da gestão de pessoas, recrutamento e seleção de novos talentos e a influência da cultura no desenvolvimento da liderança. A metodologia aplicada foi a descritiva, aplicou-se um questionário semi-estruturado contendo 33 questões fechadas, na região Nordeste e região Sul, Com a análise quantitativa foi possível constatar que um colaborador satisfeito eleva o nível de competitividade e melhora o desempenho da empresa. Dessa forma, mostra-se a necessidade de se investir no capital humano para uma acirrada competitividade de mercado. Como resultados, foi possível perceber que alguns fatores possuem diferença entre as regiões como: remuneração, nível de escolaridade e percepção de benefícios da empresa. Conclui-se que, mesmo sendo a mesma empresa, existe uma diferença na percepção dos colaboradores referente à satisfação.
\end{abstract}

Palavras-Chaves: Satisfação. Retenção. Gestão de pessoas.

\section{THE INFLUENCE OF REGIONAL CULTURES IN THE DEVELOPMENT OF LEADERSHIPS AND THE SATISFACTION PROCESS}

\begin{abstract}
The present study has the objective of verifying the satisfaction and retention of the administrative managers, in a large retail company, analyzing two different regions of Brazil. Theoretical definitions presented in the literature review, with concepts about employee satisfaction and retention, the importance of keeping them satisfied, the evolution of people management, recruitment and selection of new
\end{abstract}

\footnotetext{
${ }^{1}$ Bacharel em Administração pela Faculdade Metodista de Santa Maria/FAMES

${ }^{2}$ Mestre em Engenharia de Produção pela Universidade Federal de Santa Maria/UFSM

${ }^{3}$ Mestra em Gestão de Organizações Públicas pela Universidade Federal de Santa Maria/UFSM

${ }^{4}$ Doutoranda em Administração no Programa de Pós-Graduação em Administração da Universidade Federal de Santa Maria/UFSM

${ }^{5}$ Especialista em Acupuntura; Fisioterapeuta pelo Centro Universitário Franciscano/UNIFRA

${ }^{6}$ Mestrando em Administração na Universidade Federal de Santa Maria/UFSM
} 
talents, and the influence of culture on the development of leadership. The applied methodology was descriptive, a semi-structured questionnaire was applied containing 33 closed questions, in the Northeast region and South region. With the quantitative analysis it was possible to verify that a satisfied employee raises the level of competitiveness and improves the performance of the company. Thus, it is necessary to invest in human capital for a strong market competitiveness. As results, it was possible to perceive that some factors have differences among the regions as: remuneration, level of schooling and perception of benefits of the company. It is concluded that, even though it is the same company, there is a difference in employees' perception of satisfaction.

Keywords: Satisfaction. Retention. People management.

\section{Resumen}

El presente estudio tiene el objetivo de verificar la satisfacción y retención de los gestores administrativos, en una gran empresa del comercio al por menor, analizando dos diferentes regiones de Brasil. Se han encontrado definiciones teóricas presentadas en la revisión de literatura, con conceptos sobre satisfacción y retención de colaboradores, la importancia de mantenerse satisfechos, la evolución de la gestión de personas, reclutamiento y selección de nuevos talentos y la influencia de la cultura en el desarrollo de la cultura liderazgo. La metodología aplicada fue la descriptiva, se aplicó un cuestionario semi-estructurado que contenía 33 cuestiones cerradas, en la región Nordeste y región Sur, Con el análisis cuantitativo fue posible constatar que un colaborador satisfecho eleva el nivel de competitividad y mejora el desempeño de la empresa. De esta forma, se muestra la necesidad de invertir en el capital humano para una fuerte competitividad de mercado. Como resultados, fue posible percibir que algunos factores poseen diferencia entre las regiones como: remuneración, nivel de escolaridad y percepción de beneficios de la empresa. Se concluye que, aun siendo la misma empresa, existe una diferencia en la percepción de los colaboradores referente a la satisfacción.

Palabras-claves: Satisfacción. Retención. Gestión de personas.

\section{INTRODUÇÃO}

O mundo, cada vez mais competitivo nos negócios, exige que as empresas mantenham altos níveis de motivação das pessoas e satisfação no trabalho que estão exercendo. Empregados motivados e satisfeitos tendem a proporcionar melhores resultados e desempenho das suas funções dentro das organizações. Motivação é o que estimula as pessoas a agir, e obter o seu próprio nível de satisfação pessoal (MARRAS, 2005). 
Sabe-se que, todos tem o direito de trabalhar em um ambiente que proporcione satisfação e bem-estar, pois dessa forma será possível um melhor desempenho nas atividades. Esta necessidade de melhores condições de trabalho surgiu a partir da revolução industrial. Desde, então, as empresas têm se preocupado em proporcionar aos seus colaboradores uma qualidade de vida no trabalho que seja reconhecida pelos seus clientes internos, buscando com isso, reter colaboradores capacitados e promissores para atuarem nas organizações.

O mercado de trabalho, necessita que as empresas tratem seus colaboradores como parceiros, seus verdadeiros capitais intelectuais, não apenas como operários, devendo orientá-los e treiná-los, aguçando sua vontade de crescimento junto à empresa

Sob essa perspectiva, as organizações precisam dos seus empregados, para atingir metas e objetivos. Atualmente, com a pressão e a competitividade geradas pela globalização, tanto a qualidade do produto, quanto o relacionamento empresa-clientes, são de grande relevância para a fidelização e retenção de novos clientes.

Chiavenato (2012) reforça que hoje as organizações precisam de pessoas com talentos, o que é indispensável para o sucesso. Para que as empresas possam manter estes colaboradores, deve saber atrair, desenvolver, monitorar, reter e recompensar, reconhecendo o potencial que cada colaborador possui. A satisfação no ambiente de trabalho, por parte do cliente interno, proporciona à empresa um melhor desempenho e produtividade de seus colaboradores para o alcance de objetivos e metas estipuladas pelas organizações.

As empresas precisam abandonar a ideia de que, as pessoas trabalham somente pela remuneração, ou seja, lembrar que os indivíduos possuem valores e princípios que precisam ser respeitados. Sendo assim, é necessário mudar a forma de visão em relação aos seus colaboradores, passando a enxergá-los como principais parceiros.

Por mais claro que seja compreender a importância da satisfação do funcionário, para um bom desenvolvimento da empresa, ainda existe a dificuldade de parametrizar, por se tratar de um estado emocional agradável resultante da avaliação que o próprio indivíduo faz do seu trabalho.

Sabe-se que o Brasil é miscigenado, por englobar sujeitos de várias culturas, por isso o fator de satisfação, em um determinado território, pode não ser para outro, cabendo ao profissional avaliar se o seu trabalho está lhe favorecendo e atendendo aos objetivos e valores considerados como importantes para sua vida dentro da empresa. 
Em face a essas considerações, este artigo tem como escopo desenvolver uma pesquisa, cujo tema é a satisfação no trabalho e sua relação com aspectos culturais em diferentes regiões do Brasil de uma grande empresa do varejo. Partindo desse contexto, este estudo tem como problemática: Quais são os índices de satisfação e retenção dos Gestores Administrativos de uma grande empresa do Varejo das Regiões Sul e Nordeste do Brasil? Em decorrência disso, o objetivo geral buscou: verificar quais aspectos regionais que estão relacionados com a satisfação e retenção dos gestores administrativos, em uma grande empresa do varejo, em diferentes regiões do país. Como objetivos específicos propõem-se: i) analisar as variáveis que contribuem negativamente e positivamente para a satisfação dos gestores administrativos das unidades em estudo; ii) comparar e analisar quais os índices que obtiveram maior e menor destaque por região; iii) identificar quais variáveis contribuem para a retenção dos gestores administrativos na empresa em estudo.

Assim, para obter os objetivos propostos, o estudo está organizado em 5 seções, sendo a primeira, a introdução. A segunda seção trata da revisão bibliográfica, considerando o que os autores escrevem sobre o assunto. A terceira seção aborda a metodologia utilizada para analisar a satisfação e retenção dos gestores administrativos. $\mathrm{Na}$ quarta seção, são apresentados os resultados encontrados e as análises das entrevistas realizadas. E na quinta seção, são demonstradas as considerações finais e a importância desta pesquisa.

\section{REVISÃO DE LITERATURA}

A satisfação no trabalho e a retenção de colaboradores vem sendo debatidas dentro das organizações, pois o bem-estar e o contentamento, são preocupações não só dos trabalhadores, mas também dos gestores, a fim de conservar e valorizar seus colaboradores, devido à grande dificuldade por parte das empresas de encontrar mão-deobra qualificada.

\subsection{CONCEITO E EVOLUÇÃO DA GESTÃO DE PESSOAS}

A gestão de pessoas é uma associação de habilidades, métodos, técnicas, práticas e políticas que tem como objetivo administrar o comportamento interno dos colaboradores e desenvolver o capital intelectual da empresa, incentivando-os para o 
crescimento. Ela teve seu surgimento após a Revolução Industrial, buscando equilíbrio entre as organizações e colaboradores, tornando-se um setor fundamental para as empresas (CHIAVENATO, 2012).

De acordo com Chiavenato (2012), o setor que tinha relação direta com os colaboradores chamava-se Relações Industriais (RI), que durante anos tratou seus funcionários de forma incisiva, sem que eles pudessem opinar ou contribuir com suas ideias. Posteriormente, recebeu a denominação de Recursos Humanos (RH), adotando uma nova postura mediante seus colaboradores. Com essa nova, nomenclatura os integrantes da empresa passaram a ser mais valorizados, sendo parte do patrimônio da empresa como um capital intelectual. Atualmente conhecida como Gestão de Pessoas (GP), a área apresenta uma maior dinâmica entre colaborador e empresa.

A gestão de pessoas busca a colaboração de forma intensa dos funcionários. Para isso é necessário tratá-los como peças-chave. Para Robbins (2008) os seres humanos são essencialmente folhas de papel em branco que são escritas pelo ambiente. Cabe à empresa saber administrar e moldar os colaboradores de forma a contribuir com seus resultados, pois os mesmos não estiverem em busca do mesmo ideal, podem prejudicar o foco da organização.

Conforme Chiavenato (2012), com a evolução tecnológica e dos ideais dos profissionais, a gestão de pessoas também teve que progredir. Antes, o departamento de recursos humanos limitava-se a apenas recrutar profissionais. Hoje, além de selecionar, precisa estar em constante treinamento para reciclar seus colaboradores, garantindo o sucesso no desenvolvimento das empresas. Conforme Vasconcelos (2001), é necessário se viver bem dentro da empresa, pois é nela que as pessoas passam a maior parte de suas vidas.

\footnotetext{
A moderna Gestão de Pessoas consiste de várias atividades integradas, como descrição e análise de cargos, planejamento de RH, recrutamento, seleção, orientação e motivação das pessoas, avaliação de desempenho, remuneração, treinamento e desenvolvimento, relações sindicais, segurança, saúde e bemestar, etc. (CHIAVENATO, 2012, p.13)
}

Devido à demanda de tarefas e a complexidade de se administrar pessoas, o setor de Recursos Humanos precisou se modernizar, adequando-se a nova gestão de pessoas, para que se pudesse controlar melhor a administração geral. Segundo Chiavenato (2012), o gestor, na sua atribuição, necessita desempenhar as quatro funções administrativas: planejar, organizar, dirigir e controlar, com o enfoque em formar 
equipes para desempenhar juntos as tarefas com excelência, para o alcance de objetivos e metas estipuladas pelas organizações.

Para Gil (2001), a Gestão de Pessoas é a função gerencial que visa à cooperação das pessoas que atuam nas organizações para o alcance dos objetivos tanto organizacionais quanto individuais. O gestor é responsável por dar o primeiro impulso, motivar, gerir, selecionar e acompanhar o desenvolvimento da sua equipe. Para isso acontecer, ele também deve estar preparado para liderar seu grupo. Segundo Hunter (2004, p. 28), liderança "é a habilidade de influenciar pessoas para trabalharem entusiasticamente visando atingir os objetivos identificados como sendo para o bem comum".

\subsection{RECRUTAMENTO E SELEÇÃO}

O recrutamento é um conjunto de técnicas utilizado para atrair candidatos qualificados, capaz de suprir as necessidades que a empresa estabelece. É um sistema de informação através da qual a empresa divulga as oportunidades de emprego que deseja preencher (CHIVANETO, 2012).

Existem várias formas de recrutamento, entre elas se destacam o interno, no qual é divulgada a vaga somente dentro da empresa, proporcionando aos já colaboradores uma forma de incentivar seu crescimento profissional, motivando-os com novos desafios e novos aprendizados. Esse tipo de recrutamento também é oportuno para a empresa, pois é uma forma de manter o colaborador, incentivando a sua permanência e fidelidade na organização.

Embora recrutamento lembre agências de emprego e anúncios classificados, preencher vagas internas com pessoas já empregadas na empresa é frequentemente a melhor alternativa de recrutamento (DESSLER, 2003 p.76).

Há também o recrutamento externo, no qual a vaga é divulgada fora da empresa, abrangendo os trabalhadores que estão fora da organização, visto, muitas vezes, pelas organizações como uma injeção de oxigênio para as organizações, devido a novas experiências, habilidades e expectativas (DESSLER, 2003).

Tanto o recrutamento interno quanto o externo apresentam vantagens e desvantagens. Para não desperdiçar novos talentos ou descoberta de já existentes, as empresas utilizam o recrutamento misto, onde a vaga é divulgada dentro das 
organizações e fora também, buscando, assim, um equilíbrio para a retenção de capital intelectual.

Depois de recrutado, a próxima etapa é selecionar o indivíduo que melhor se encaixe nas necessidades do cargo. Segundo Werther e Davis (1983) apud Pontes (1996), o processo de seleção envolve uma série de passos específicos para decidir quaise recrutados se enquadram nos pré-requisitos e devem ser contratados.

Bohlander (2005) cita que as etapas no processo de seleção e sua sequência irão variar, não somente com a empresa, mas também com o tipo e nível hierárquico dos cargos a serem preenchidos. Durante a etapa de seleção, nem todos os candidatos conseguem passar por todas elas, alguns serão descartados nos primeiros testes e entrevistas para o preenchimento da vaga. De acordo com a necessidade de habilidades e conhecimentos julgados necessários para o cargo, será realizada a seleção, observando o candidato que melhor se encaixe nos pré-requisitos estabelecidos.

\footnotetext{
A especificação do cargo, tal como foi apresentada, pode ser complementada por detalhes que facilitem na definição do perfil exato do candidato cargo. Essa especificação, mais detalhada, é chamada de características psicográficas e, portanto, visa determinar com maior exatidão aspectos voltados às aptidões, habilidades e traços comportamentais das exigências do ocupante do cargo. As características e traços a serem analisados irão variar conforme o cargo em estudo (PONTES, 1996, p. 39).
}

As técnicas de seleção podem ser classificadas em cinco grupos: entrevistas com roteiro preestabelecido, livres ou sem roteiro; provas de conhecimentos; testes psicológicos; testes de personalidades e técnicas de simulação (CHIAVENATO, 2012). Essas técnicas de seleção permitem que a organização conheça melhor seu candidato, auxiliando na tomada da decisão e determinando o sucesso ou fracasso do processo seletivo.

\subsection{GESTÃO DE TALENTOS E O PROCESSO DE SATISFAÇÃO}

Como parte integrante de um dos processos da gestão de pessoas nas organizações, a de talentos tem extrema importância, pois ajuda na manutenção dos mesmos já existentes, dentro da organização, e talentos a serem integrados na empresa. Pessoas motivadas e satisfeitas com suas atribuições proporcionam para a empresa um melhor desempenho e performance nos seus cargos. 
Ressalta Barros (2003) apud Melo et. al (2008), a retenção de talentos tende a ser fator chave, como exemplo, em processos de Fusões e Aquisições (F\&A). Neles ocorre uma evasão de talentos, causada principalmente pela insegurança gerada pela falta de lugar na nova empresa e pela perda do poder que já possuíam na organização anterior.

O talento é a matéria-prima essencial na busca de criação e na implementação de soluções diferenciadas de mercado. As organizações estão preocupadas em como atrair e reter estes talentos. Esta é uma problemática que vem aumentando, pois as mudanças do mercado se refletem nos valores e atitudes percebidas pelos jovens que procuram no trabalho autonomia e liberdade.

Para garantir uma melhor gestão de talentos é necessário dar condições para os colaboradores, proporcionar satisfação no que estão fazendo e evidenciar que a empresa valoriza seus atos e os gratifica.

\footnotetext{
Para se manterem competitivas a longo prazo, as empresas precisam saber adaptar-se. Os cargos estão se tornando mais flexíveis para lidar com as mudanças e as empresas estão adotando formas alternativas de conceber o trabalho, que levem em consideração os diversos interesses e formações dos funcionários em potencial (BOHLANDER, 2005, p.178).
}

Para Girardi (2012), a prospecção da carreira é outro ponto positivo, na qual pessoas do nível operacional passam para o gerencial ou mesmo estratégico da empresa, proporcionando um crescimento profissional, utilizando seus talentos internos. A utilização de rodízio entre as áreas de gestão (job rotation) proporciona novos desafios e perspectivas aos profissionais, servindo também para tirar o funcionário de sua zona de conforto.

As razões para uma empresa assumir a visão de parceria, considerar assim seus colaboradores, são simples. Se o empregado não se sentir parte integrante da organização, ele não conseguirá agregar valor ao seu trabalho e consecutivamente, não proporcionará à empresa o resultado que ela precisa (MARRAS, 2005).

Davis e Newstrom (1992, p.130), acreditam que "a administração necessita de informações a respeito da satisfação no trabalho dos empregados, de modo a tomar decisões pertinentes, tanto no sentido de prevenir, como no de resolver problemas com os funcionários". Para que a organização tenha conhecimento do nível de satisfação do seu colaborador, e possa tomar iniciativas para corrigir possíveis insatisfações, deve-se realizar, periodicamente, avaliação do nível de satisfação para garantir conhecimento e 
possibilitar que o colaborador se expresse e contribua com sua opinião para o crescimento da empresa.

Siqueira (2008) menciona que satisfação no trabalho é um assunto que está presente entre os gestores e pesquisadores do comportamento organizacional, pois a procura pelo entendimento de como os colaboradores de uma organização se sente em relação ao seu emprego, está relacionada ao processo motivacional e reflete diretamente no desempenho da empresa.

\subsection{A INFLUÊNCIA DA CULTURA NO DESENVOLVIMENTO DA LIDERANÇA}

O comportamento dos indivíduos, muitas vezes, está relacionado aos seus valores morais e seu contexto sócio cultural. Conforme Ogburn (1964) apud Almeida (2007, p. 108), “definiu a cultura como um espaço complexo, onde estão incluídos os conhecimentos, as crenças, as artes, os valores morais, as leis e os costumes, assim como qualquer outra capacidade ou hábito adquirido pelo indivíduo, enquanto membro de uma sociedade”. Segundo Marras (2005, p. 51) “os indivíduos, em geral, só tomam consciência do seu sistema de valores quando este é ameaçado por uma cultura alienígena".

Assim, cultura e espaço encontram-se, intimamente, ligados a uma demarcação física de território, fazendo entender que cada cultura possui suas próprias fronteiras, simbólica ou material. Mesmo nas organizações, as pessoas não estão imunes às barreiras culturais. Muitas vezes acabam por se adaptar a certa cultura, tanto da região quanto da empresa para obter seu crescimento profissional e pessoal (MARRAS, 2005).

Para garantir um melhor desenvolvimento, tanto a empresa quanto a liderança, precisam estar atentas aos fatores culturais, proporcionando flexibilidade de acordo com cada região. Vergara (2003) cita que uma liderança deve estar em constante processo de aprendizagem, "a palavra caminho é importante. Ela sinaliza o fato de que liderança é um processo, não um produto acabado" (VERGARA, 2003, p. 87).

Para Gil (2007, p. 43)

\footnotetext{
Abordar temas relacionados à cultura organizacional constitui um dos mais delicados empreendimentos no campo da administração, já que envolve aspectos que as empresas mais valorizam e que muitas vezes constituem a própria razão de sua existência. Cabe considerar, no entanto, que as empresas que promovem seu ajustamento cultural em relação às mudanças ambientais apresentam melhores condições para desenvolver-se quando comparadas às mais rígidas em relação aos estímulos externos.
} 
A interferência cultural acaba sendo imposta pelo próprio sistema capitalista vigente, na medida em que nega qualquer prioridade de discussão sobre outras questões de interesses. Cabe ao profissional adaptar-se ao ambiente em que está inserido para que consiga trilhar um amplo caminho profissional. (MARRAS, 2005).

\section{MÉTODO}

Marconi e Lakatos (2007) definem pesquisa como um procedimento formal, com métodos e pensamentos reflexivos, que requerem um tratamento científico e se aprimoram no caminho, possibilitando conhecer a realidade ou descobrir verdades parciais. O presente estudo caracteriza-se como uma pesquisa bibliográfica e descritiva. A pesquisa bibliográfica trata de um levantamento da bibliografia existente em publicações de artigos, livros, revistas, entre outros. Tem como finalidade colocar o pesquisador em contato com o que já foi pesquisado sobre o assunto (MARCONI; LAKATOS, 2007).

Conforme Vergara (2000), a pesquisa descritiva, por sua vez, expõe as características de determinada população e fenômeno, estabelecendo correlação entre as variáveis. Segundo Gil (2001, p. 42), a pesquisa descritiva tem o objetivo de "estudar as características de um grupo: sua distribuição por idade, sexo, procedência, nível de escolaridade, estado de saúde física e mental, etc.”.

Para o desenvolvimento do trabalho será utilizada a estratégia de multicasos, citado por Yin (1989) apud Filho (2002), que permite observar evidências em diferentes contextos, pela replicação do fenômeno, sem necessariamente se considerar a lógica de amostragem. Para a realização do estudo, serviram de base 6 filiais do Grupo Magazine Luiza, distribuídos entre as regiões Sul e Nordeste.

Para a coleta dos dados utilizou-se um instrumento adaptado de Mello (2014), contendo 33 perguntas fechadas. Onde a primeira parte visou identificar o perfil dos pesquisados, já a segunda parte foi destinada a avaliar a satisfação e retenção de gestores administrativos, levando em consideração as influências culturais dos estados pesquisados. Para essa análise utilizou-se uma escala do tipo Likert.

Após a coleta dos dados, os mesmos foram analisados de forma quantitativa, e os resultados expressos em forma de tabela para melhor compreensão do leitor. Entende-se por pesquisa quantitativa aquela que parte de uma formulação matemática e exprime 
uma relação quantitativa, utilizando técnicas estatísticas, sendo estas extraídas de questionários, de uma determinada população (SEVERINO, 2007).

\section{CARACTERIZAÇÃO DA EMPRESA E ANÁLISE DOS RESULTADOS}

\subsection{EMPRESA}

Em 16 de novembro de 1957, dava início as suas atividades uma das maiores empresas do varejo no Brasil, inicialmente, se chamava "A Cristaleira", fundada pelo casal SR. Pelegrino José Donato e D. Luiza Trajano Donato. Em 1974, foi inaugurada a primeira grande loja de departamentos, localizada na cidade de Franca - SP.

Em junho de 2011, foi aberto o processo de Oferta Pública Inicial de Ações (IPO), um passo muito importante para a estratégia e trajetória de crescimento, permitindo o acesso a uma fonte alternativa de financiamento dos investimentos, geração de empregos e criação de valor para os acionistas.

Atualmente, existem 744 lojas espalhadas por diversas cidades do Brasil, que conta com a colaboração de 26.600 funcionários diretos, gerando mais empregos indiretos como carreteiros, montadores terceirizados e empresas que prestam serviços para a mesma.

\subsection{ANÁLISE DO PERFIL DOS GESTORES DOS ESTADOS PESQUISADOS}

Para a realização desse estudo optou-se pela escolha das regiões Sul (Rio Grande do Sul, Santa Catarina e Paraná) e pela região Nordeste (Bahia, Paraíba e Pernambuco). Dentre os Estados escolhidos, foram analisadas as principais filiais, as que possuem maior volume de vendas, uma média de vendas mês acima de 1 milhão de reais.

A Tabela 1 demonstra o perfil dos gestores pesquisados, como também suas cidades, seu tempo de empresa e sua remuneração.

Tabela 1 - Perfil dos Gestores Pesquisados da Região Sul e Nordeste 


\begin{tabular}{|c|c|c|c|c|c|c|c|c|c|c|c|}
\hline \multicolumn{3}{|c|}{ Tabela 1} & \multirow{2}{*}{\begin{tabular}{|c|} 
SEXO \\
$F$ \\
\end{tabular}} & \multirow{2}{*}{\begin{tabular}{|c|} 
IDADE \\
43 \\
\end{tabular}} & \multirow{2}{*}{\begin{tabular}{|c|}
$\begin{array}{c}\text { TEMPO } \\
\text { DE } \\
\text { EMPRESA }\end{array}$ \\
12 anos \\
\end{tabular}} & \multirow{2}{*}{\begin{tabular}{|l} 
INSTRUÇÃO \\
Ensino Médio
\end{tabular}} & \multirow{2}{*}{\begin{tabular}{|c|} 
DEFICIÊNCIA \\
não \\
\end{tabular}} & \multirow{2}{*}{$\begin{array}{l}\text { ESTAD } \\
\text { O CIVIL } \\
\text { divorciad }\end{array}$} & \multirow{2}{*}{\begin{tabular}{|c|} 
FILHOS \\
1 \\
\end{tabular}} & \multirow{2}{*}{\begin{tabular}{|l|} 
SALÁRIO \\
$\begin{array}{l}\text { De } R \$ 1530,01 \\
\text { à } R \$ 3060,00\end{array}$ \\
\end{tabular}} & \multirow{2}{*}{\begin{tabular}{|l|}
\multicolumn{1}{|c|}{$\begin{array}{c}\text { AVALIAÇÃO } \\
\text { DE } \\
\text { DESEMPENHO }\end{array}$} \\
$\begin{array}{l}\text { Acima da Média } \\
\text { da Empresa }\end{array}$ \\
\end{tabular}} \\
\hline \multirow{7}{*}{ ESTADO } & \multirow{3}{*}{ SUL } & PORTO ALEGRE & & & & & & & & & \\
\hline & & FLORIANÓPOLIS & $\mathbf{F}$ & 23 & 5 anos & \begin{tabular}{|l} 
Superior \\
Incompleto
\end{tabular} & não & casada & 1 & $\begin{array}{l}\text { De R\$ } 1530,01 \\
\text { à } R \$ 3060,00\end{array}$ & $\begin{array}{l}\text { Acima da Média } \\
\text { da Empresa }\end{array}$ \\
\hline & & CURITIBA & $\mathbf{F}$ & 27 & 6 anos & $\begin{array}{l}\text { Superior } \\
\text { Incompleto }\end{array}$ & não & casada & 1 & $\begin{array}{l}\text { De R\$ } 1530,01 \\
\text { à } R \$ 3060,00\end{array}$ & $\begin{array}{l}\text { Acima da Média } \\
\text { da Empresa }\end{array}$ \\
\hline & & & & & & & & & & & \\
\hline & \multirow{3}{*}{ NORDESTE } & SALVADOR & $\mathbf{F}$ & 31 & 2 anos & \begin{tabular}{|l} 
Superior \\
Incompleto
\end{tabular} & não & solteira & 1 & \begin{tabular}{|l} 
De $R \$ 1530,01$ \\
à $R \$ 3060,00$
\end{tabular} & $\begin{array}{l}\text { Entre os } \\
\text { Melhores da } \\
\text { Empresa }\end{array}$ \\
\hline & & RECIFE & $\mathbf{F}$ & 27 & 9 anos & Ensino Médio & não & casada & 1 & $\begin{array}{l}\text { De R\$ } 1020,01 \\
\text { à } R \$ 1530,00\end{array}$ & $\begin{array}{l}\text { Na Média da } \\
\text { Empresa }\end{array}$ \\
\hline & & JOÃO PESSOA & $\mathbf{M}$ & 25 & 4 anos & Ensino Médio & não & solteiro & 0 & $\begin{array}{l}\text { De } R \$ 1020,01 \\
\text { à } R \$ 1530,00\end{array}$ & $\begin{array}{l}\text { Acima da Média } \\
\text { da Empresa }\end{array}$ \\
\hline
\end{tabular}

Fonte: Elaborada pelos autores (2016)

De acordo com os dados analisados na Tabela 1, pode-se identificar que, tanto na região Sul, quanto na Nordeste, o cargo de Gestor Administrativo é ocupado mais pelo sexo feminino, a média de idade dos Gestores da região Sul ficou em 31 anos, já na região Nordeste tem-se uma média de 28 anos.

No que se refere ao tempo de empresa observa-se que na região Sul os colaboradores com mais tempo de organização, possui média de 8 anos de empresa, já na região Nordeste, a média é de 5 anos. O que se refere ao grau de instrução verificouse que na região Sul 66,67\% dos Gestores apresentaram ensino superior incompleto e $33,33 \%$ ensino médio completo. Na região Nordeste, $66,67 \%$ possuem ensino médio completo e $33,33 \%$ possuem superior incompleto.

Conforme pesquisa divulgada pelo IBGE (2015), apenas 16\% dos trabalhadores possuem ensino superior completo, na região Nordeste onde a maior parte da população ocupada $(40,7 \%)$ não cursou nem o ensino fundamental. Já na região Sul, ocorre o inverso, no RS, o percentual das pessoas que concluíram o Ensino Médio é superior ao das demais regiões atingindo 51,8\%. Ainda conforme pesquisa do IBGE (2015), 4,8\% da população de trabalhadores não possui nenhum nível de instrução, $10,8 \%$ possuem ensino fundamental completo, $25,6 \%$ ensino fundamental incompleto, $31,1 \%$ ensino médio completo, $6,3 \%$ ensino médio incompleto, $16,03 \%$ superior completo e $5,3 \%$ superior incompleto (FREITAS, 2015). Em nenhuma das regiões, foi apontado gestor com alguma deficiência física ou psicológica.

Outro aspecto analisado foi o estado civil, onde $66,67 \%$ dos gestores são casados e $33,33 \%$ são divorciados, na região Nordeste $66,67 \%$ são solteiros e $33,33 \%$ casados. Em relação a quantidade de filhos na região Sul, todos afirmaram possuir filhos, em 
média um, e na região Nordeste dois colaboradores possuem filhos, em média também de um.

No que se refere a renda mensal, observou que o maior percentual na região Sul (100\%) possui renda entre $\mathrm{R} \$ 1.530,01$ à $\mathrm{R} \$ 3.060,00$. Na região Nordeste, 66,67\% possui renda entre $\mathrm{R} \$ 1.020,01$ à $\mathrm{R} \$ 1.530,00$ e apenas 33,33\% possui renda entre $\mathrm{R} \$ 1.530,01$ à $\mathrm{R} \$ 3.060,00$. A renda média do brasileiro em 2015 chegou a $\mathrm{R} \$ 1.113,00$, as estimativas de rendimento nominal domiciliar per capita em 2015, para as 27 unidades da Federação, são decorrentes da Pesquisa Nacional por Amostra de Domicílios (PNAD), divulgadas pelo IBGE em fevereiro de 2016.

Quanto a avaliação de desempenho, temos $100 \%$ dos gestores da região Sul acima da média da empresa. Na região Nordeste, 33,33\% apresentaram a mesma, $33,33 \%$ entre os melhores da empresa e, 33,33\% acima da média da empresa.

\subsection{ASPECTOS CULTURAIS QUE INFLUENCIAM A GESTÃO}

Com o objetivo de identificar os principais fatores que podem afetar a gestão dos mais diferentes Estados, buscou-se verificar a satisfação e a retenção dos Gestores Administrativos em relação aos aspectos culturais de cada região. Alcançaram-se, assim, os índices de satisfação e/ ou importância apresentados na Tabela 2.

Tabela 2 - Aspectos positivos no que tange a satisfação da Região Sul

\begin{tabular}{l|r}
\hline $\begin{array}{l}\text { Eu recomendaria aos meus parentes e amigos esta empresa como um excelente lugar para se } \\
\text { trabalhar; }\end{array}$ & 4,67 \\
\hline $\begin{array}{l}\text { A empresa atende adequadamente às minhas necessidades nas áreas de saúde e outros } \\
\text { benefícios; }\end{array}$ & 4,67 \\
\hline Considero que trabalhar nesta empresa vem tornando a minha vida melhor; & 4,67 \\
\hline Acredito que trabalhando nesta empresa terei oportunidade de fazer carreira e crescer; & 5,00 \\
\hline Gosto do trabalho que realizo hoje nesta empresa; & 5,00 \\
\hline
\end{tabular}

Fonte: Elaborada pelos autores (2016)

Considerando as questões propostas no instrumento de pesquisa, foram selecionadas as cinco melhores médias da região Sul. Onde foi possível identificar que 
os gestores administrativos da empresa recomendariam a seus parentes e amigos, como um lugar excelente para se trabalhar, atingindo uma média de 4,67. Com média 5,00 onde todos os respondentes apontaram a melhor nota, diz gostarem do trabalho que realizam hoje na organização. Conforme Marras (2005), os valores culturais de uma empresa são tidos como extremamente importantes na consecução dos resultados da companhia. Acreditam que trabalhando na empresa terão oportunidade de fazer carreira e crescer, onde todos os respondentes elencaram nota máxima atingindo uma média de 5,00. A globalização e o aumento da competitividade enfatizam a importância de programas de desenvolvimento de lideranças, relevantes e efetivos (DESSLER, 2003).

Com média 4,67 os gestores da região Sul afirmaram que a empresa atende adequadamente às necessidades nas áreas de saúde e outros benefícios. Chiavenato (2012) define benefícios como recompensas ou vantagens não financeiras baseadas no fato de pertencer à organização e que são oferecidas aos colaboradores a fim de atrair e reter talentos.

Ainda referente ao questionário aplicado na região Sul identifica-se às cinco questões com as médias mais baixas, conforme Tabela 3.

Tabela 3 - Aspectos negativos no que tange a satisfação da Região Sul

\begin{tabular}{l|c}
\hline Como avalia a ergonomia do seu ambiente de trabalho; & 3,00 \\
\hline Como você analisa a rotatividade de colaboradores na sua empresa; & 3,00 \\
\hline $\begin{array}{l}\text { Considero que o tempo que dedico ao meu trabalho é equilibrado entre as necessidades da } \\
\text { empresa e as minhas necessidades e familiares; }\end{array}$ & 3,33 \\
\hline Sinto-me satisfeito com a minha jornada de trabalho; & 4,00 \\
\hline A empresa utiliza critérios justos para promoção e carreira; & 4,00 \\
\hline
\end{tabular}

Fonte: Elaborada pelos autores (2016)

Foi possível identificar que os gestores administrativos da região Sul consideram que o tempo que dedicam ao trabalho é equilibrado entre as necessidades da empresa e 
as necessidades familiares, obtendo uma média de 3,33. Siqueira (2008) considera que os níveis de satisfação dos colaboradores, pode ser uma forma de monitorar o quanto as empresas promovem e protegem a saúde e o bem-estar dos que contribuem com a organização. Esta visão compreende que os sentimentos, que são emitidos no âmbito do trabalho, possam refletir para a vida pessoal, familiar e social dos funcionários.

Com média 3,00 destaca-se que a percepção dos gestores de que o turnover da empresa está um pouco alto. Ainda com a mesma média, a ergonomia do local de trabalho, obteve uma nota baixa. Segundo Dessler (2003), a demissão deve ocorrer somente depois que todas as tentativas de reabilitação do colaborador tenham se esgotado.

Referente a satisfação da jornada de trabalho, esta questão obteve média 4,00, ainda com a mesma média, a percepção dos gestores administrativos identifica que eles acham justos os critérios para promoção e carreira propostas pela empresa. Talentos são necessário, é preciso saber atrair, desenvolver, reter e recompensar (CHIAVENATO, 2012).

Considerando as questões propostas no questionário, foram selecionadas às cinco melhores médias da região Nordeste, conforme Tabela 4.

Tabela 4 - Aspectos positivos no que tange a satisfação da Região Nordeste

\begin{tabular}{l|r}
\hline Recebo todas as informações que preciso para fazer bem o meu trabalho; & 4,67 \\
\hline $\begin{array}{l}\text { As pessoas de qualquer idade, raça, cor e orientação sexual são tratadas com mesma justiça e } \\
\text { respeito nesta empresa; }\end{array}$ & 4,67 \\
\hline Acredito que trabalhando nesta empresa terei oportunidade de fazer carreira e crescer; & 5,00 \\
\hline $\begin{array}{l}\text { Eu recomendaria aos meus parentes e amigos esta empresa como um excelente lugar para se } \\
\text { trabalhar }\end{array}$ & 5,00 \\
\hline Gosto do trabalho que realizo hoje nesta empresa; & 5,00 \\
\hline
\end{tabular}

Fonte: Elaborada pelos autores (2016)

Foi possível identificar que os gestores administrativos da empresa a recomendariam aos seus parentes e amigos como um excelente lugar para se trabalhar, 
obtendo média 5,00. Ainda com a mesma média, os respondentes afirmaram gostar do trabalho que realizam na empresa e acreditam que executando suas atividades, terão oportunidade de desenvolver sua carreira e ter crescimento profissional. Há várias formas de contribuir para o desenvolvimento de carreira de um colaborador e, ao mesmo tempo, atender as necessidades da empresa. A organização pode, certamente, ser uma força positiva no processo de desenvolvimento, mas a responsabilidade primária para o crescimento ainda é do indivíduo (BOHLANDER, 2005).

Com média 4,67 os respondentes informaram receber todas as informações necessárias para fazer bem seu trabalho. Conforme Junior (2010), deve haver uma mudança profunda nas empresas, onde as lideranças se preocupam, não somente com a maneira de se gerenciar os processos produtivos, mas principalmente, no modo de conduzir o relacionamento humano com esses processos.

Ainda com a mesma nota foi possível identificar que as pessoas de qualquer idade, raça, cor e orientação sexual são tratadas com mesma justiça e respeito nesta empresa.

Ainda referente a região Nordeste, identifica-se às cinco questões com as médias mais baixas, conforme apresenta a Tabela 5 .

Tabela 5 - Aspectos Negativos no que tange a satisfação da Região Nordeste

\begin{tabular}{l|r}
\hline $\begin{array}{l}\text { Considero que o tempo que dedico ao meu trabalho é equilibrado entre as necessidades da } \\
\text { empresa e as minhas necessidades e familiares; }\end{array}$ & 3,67 \\
\hline A quantia que recebo como remuneração variável ou participação nos lucros é justa; & 3,67 \\
\hline A empresa utiliza critérios justos para promoção e carreira; & 4,00 \\
\hline $\begin{array}{l}\text { Considero que meu trabalho é reconhecido e valorizado pela empresa; } \\
\text { A empresa atende adequadamente às minhas necessidades nas áreas de saúde e outros } \\
\text { benefícios; }\end{array}$ & 4,00 \\
\hline
\end{tabular}

Fonte: Elaborada pelos autores (2016)

Com 3,67 os gestores da região Nordeste consideram que o tempo que dedicam ao trabalho é equilibrado entre as necessidades da empresa e as necessidades familiares. 
Com a mesma média afirmaram achar justa a remuneração variável ou participação nos lucros da empresa. Segundo Junior (2010), a remuneração estabelecida pela organização, expressa a valorização atribuída aos empregados, uma remuneração acima da média do mercado só pode ser sustentada em um ambiente competitivo onde a empresa consiga se manter com o desempenho acima da média.

Com média 4,00 os respondentes consideram que o trabalho, por eles realizado, é reconhecido e valorizado pela empresa. Com a mesma média, afirmaram achar justo o critério. Marras (2005) ressalta que as empresas de ponta têm se preocupado com a carreira dos colaboradores por saber claramente o quanto isto é motivador para o ser humano.

Ainda com média 4,00 os gestores da região Nordeste consideram que a empresa atende adequadamente as suas necessidades nas áreas de saúde e outros benefícios. Conforme Chiavenato (2012), a oferta de benefícios e serviços prestados pelas empresas aos seus empregados, influência diretamente no grau de qualidade de vida na organização.

\section{CONSIDERAÇÕES FINAIS}

As organizações estão cada vez mais preocupadas em reter bons talentos, para que possam obter um crescimento em relação ao mercado. Buscando assim, a satisfação dos colaboradores, o crescimento da organização e ganho de mercado, indiferente do estado que esteja alocado.

Este trabalho objetivou verificar a satisfação e retenção dos gestores administrativos, em uma grande empresa do varejo, analisando duas diferentes regiões do Brasil.. As regiões são a Sul e a Nordeste, sendo que a escolha por essas regiões se deu pelo fato de possuírem características culturais diferenciadas.

Ao identificar as variáveis que afetam a organização de forma positiva ou negativa, nas duas regiões, foi possível concentrar os esforços em ações pontuais, voltadas e centradas para os seus aspectos culturais, os quais devem ser respeitados.

Com base na pesquisa realizada, foi possível identificar algumas diferenças entre a região Sul e Nordeste, começando pelo nível de escolaridade, em que a região Sul, a maioria dos gestores administrativos possui nível superior incompleto, na região Nordeste destaca valor da renda mensal inferior ao valor do estado do Sul. 
A pesquisa possibilitou observar que a satisfação de se trabalhar na empresa, tanto na região Sul, quanto Nordeste possui algumas variáveis. Em ambas, os colaboradores indicariam a seus familiares e amigos como um excelente local para se trabalhar, como também a possibilidade de crescimento e plano de carreira. Já no que se refere a benefícios e área de saúde, foi possível identificar que a percepção é diferente entre as regiões, como também referente a remuneração, onde na região Nordeste obteve-se uma menor média.

Portanto, conclui-se que mesmo sendo a mesma empresa, existe uma diferença na percepção dos colaboradores referente a satisfação, como também a diferença do nível cultural entre as regiões, sendo o mesmo cargo pesquisado. Porém, sabe-se que um estudo nunca termina com seus resultados. Assim, como proposta para estudos futuros, sugere-se a reaplicação dessa pesquisa em todas as regiões brasileiras, possibilitando assim, um comparativo macro de todo o território, servindo de base gerencial para a tomada de decisão.

\section{REFERÊNCIAS}

ALMEIDA, F J R Almeida. Ética e Desempenho Social das Organizações: um Modelo Teórico de Análise dos Fatores Culturais e Contextuais. Rev. Adm. Contemp. v 11 n. 3 Curitiba July/Sept. 2007.

BARROS, A J da Siqueira; LEHFELD, N A de Souza; Fundamentos de metodologia científica: um guia para iniciação científica. 2. ed. São Paulo: Pearson Education, 2000.

BOHLANDER, G W. Administração de Recursos Humanos. São Paulo: Pioneira Thomson Learning 2005.

CHIAVENATO, Idalberto. Gestão de Pessoas: Princípios da administração: o essencial em teoria geral da administração. Idalberto Chiavenato. 2 ed. Barueri, SP; Manole, 2012.

DAVIS, K; NEWSTROM, J W. Comportamento Humano no Trabalho. Uma abordagem psicológica. São Paulo. Pioneira. 1992 v.1.

DESSLER, G. Administração de Recursos Humanos. 2ed. São Paulo: Prentice Hall, 2003.

DUNZER, G A; Melo, Eliana Medeiros Pereira, Melo, Joyce de Souza Cunha. Desafios de Atração e Retenção de Talentos - Estudo de Caso da Petrobrás, XXXII Encontro da ANPAD, Rio de Janeiro/RJ - 6 a 10 de setembro de 2008. 
FILHO, C A P Machado. Responsabilidade social corporativa e a criação de valor para as organizações: um estudo multicascos CAP Machado Filho, 2002 fundacaofia.com.br

GIL, A C. Gestão de Pessoas: enfoque nos papéis profissionais. São Paulo: Atlas, 2001.

GIL, A C. Gestão de Pessoas: enfoque nos papéis profissionais. 1 ed 7 re impr. São Paulo: Atlas, 2007.

GIRARDI, D Girardi, Kelly Cristina Benetti Tonani Tosta, Júlia de Freitas Girardi, André de Freitas Girardi. Retenção de Talentos nas Maiores Indústrias de Santa Catarina - VIII Congresso Nacional de Excelência em Gestão, 2012.

IBGE Instituto Brasileiro de Geografia e Estatística. Renda per capita.<http://agenciabrasil.ebc.com.br/economia/noticia/2016-02/ibge-renda-capitamedia-do-brasileiro-atinge-r-1113-em-2015>Acesso em: 30 maio 2016.

FREITAS, Eduardo. "IDH, escolarização no Brasil"; Brasil Escola, 2015.

<Http://agenciabrasil.ebc.com.br/economia/noticia/2016-02/ibge> Acesso em: 30 maio 2016.

MARCONI, M A; LAKATOS, E M. Metodologia do trabalho científico:

procedimentos básicos, pesquisa bibliográfica, projeto e relatório, publicações de trabalhos científicos. 7ed. São Paulo: Atlas, 2007.

MELLO, D. A. Análise dos fatores de retenção de empregos em organizações que atuam no Brasil. São Paulo, 2014.

PONTES, B R. Planejamento, recrutamento e seleção de pessoal. 2ed São Paulo: LTr, 1996.

ROBBIS, S P, Administração: mudanças e perspectivas. São Paulo: Saraiva, 2000, edição 2008.

SEVERINO, A J. Metodologia do trabalho científico. 23ed. São Paulo: Cortez, 2007.

SIMONI, C A Cocozza. Pesquisa Qualitativa em Sistemas de Informação, 2003. (Universidade Estadual de Campinas - Unicamp Instituto de Computação - IC Pesquisa Qualitativa em Sistemas de Informação Carlos Alberto Cocozza, Simoni Maria Cecília Calani Baranauskas, fevereiro de 2003).

SIQUEIRA, M M M. Medidas do comportamento organizacional. Satisfação no trabalho. São Paulo: Artmed, 2008.

VASCONCELOS, A. F. Qualidade de vida no trabalho: origem, evolução e perspectivas. Cadernos de Pesquisa em Administração, v.8, n.1, p. 23-35, 2001. VERGARA, S. Projetos e Relatórios de Pesquisa em Administração. São Paulo: Atlas, 2000. 